\title{
INTEGRAÇÃO GLOBAL E DISSOCIAÇÃO LOCAL: \\ UMA ANÁLISE TEMPORAL DO PLANEJAMENTO DE GPDUS POR MEIO DOS PROJETOS ESTAÇÃO DAS DOCAS E BELÉM PORTO FUTURO
}

\author{
Maria Eduarda Iesbich Arruda* \\ Aleph Tonera Lucas** \\ Luísa Siqueira Doebeli** \\ *Universidade Federal de Santa Catarina, Centro de Filosofia e Ciências Humanas, Programa de Pós-graduação \\ em Geografia, Florianópolis, SC, Brasil \\ **Universidade Federal de Santa Catarina, Centro Tecnológico, Departamento de Arquitetura e Urbanismo, \\ Florianópolis, SC, Brasil
}

\begin{abstract}
Resumo
O avanço das práticas internacionais de intervenção urbana nas cidades brasileiras, nas duas últimas décadas, desencadeou processos de desarticulação do planejamento urbano na escala local, perante o enfraquecimento do poder público como ator principal, e de desequilíbrio territorial, resultantes da concentração de investimentos. Nesse contexto, norteada pela incidência do modelo de planejamento urbano estratégico, a cidade de Belém (PA) destacase por abarcar dois Grandes Projetos de Desenvolvimento Urbano (GPDUs) voltados à requalificação de espaços de orla: Estação das Docas, inaugurado em 2000, e, mais recentemente, Belém Porto Futuro, de 2020. Com base na análise de ambos os projetos, o presente artigo propõe-se abordar as transformações no planejamento e na gestão desses GPDUs, considerando os fundamentos do planejamento estratégico, no que diz respeito ao caráter de submissão aos padrões de intervenção internacionais e de dissociação das demandas e do contexto urbano local.

Palavras-chave

Planejamento Estratégico; GPDUs; Requalificações Urbanas Portuárias; Integração, Reconfiguração e Desequilíbrio Econômico no Território.
\end{abstract}




\title{
GLOBAL INTEGRATION AND LOCAL DISSOCIATION: A TEMPORAL ANALYSIS ABOUT THE UDPS' PLANNING THROUGH THE ESTAÇÃO DAS DOCAS AND BELÉM PORTO FUTURO PROJECT CASES
}

\author{
Maria Eduarda Iesbich Arruda* \\ Aleph Tonera Lucas** \\ Luísa Siqueira Doebeli** \\ *Universidade Federal de Santa Catarina, Centro de Filosofia e Ciências Humanas, Programa de Pós-graduação \\ em Geografia, Florianópolis, SC, Brazil \\ ** Universidade Federal de Santa Catarina, Centro Tecnológico, Departamento de Arquitetura e Urbanismo, \\ Florianópolis, SC, Brazil
}

\begin{abstract}
The advance of international practices of urban intervention in Brazilian cities in the last two decades has exacerbated processes of disarticulation on urban planning at the local scale, due to the decline of the State as its main actor, what increases social and territorial inequality, owing to concentration of territorial investments. In this context, guided by the incidence of the strategic urban planning model, the city of Belém, in the state of Pará, stands out for encompassing two megaprojects aimed to the requalification of waterfront spaces: the Estação das Docas, inaugurated in 2000 and, more recently, the Belém Porto Futuro, inaugurated in 2020. Based on the analysis of both projects, this article aims to analyze the transformation in planning and management of these megaprojects, considering the principles of the strategic urban planning, regarding the praxis of submission to international standards of intervention and the dissociation from the local urban demands.
\end{abstract}

Keywords

Strategic Urban Planning; Megaprojects; Port Requalification; Territorial Fragmentation; Urban Environmental Inequality. 


\title{
INTEGRAÇÃO GLOBAL E DISSOCIAÇÃO LOCAL: UMA ANÁLISE TEMPORAL DO PLANEJAMENTO DE GPDUS POR MEIO DOS PROJETOS ESTAÇÃO DAS DOCAS E BELÉM PORTO FUTURO
}

\author{
Maria Eduarda Iesbich Arruda \\ Aleph Tonera Lucas \\ Luísa Siqueira Doebeli
}

Introdução

A ascensão do planejamento estratégico, em nível global, transformou significativamente as práticas na gestão e no planejamento das cidades no contexto internacional. No Brasil, autores como Vainer (1996; 2002; 2007) e Sánchez (1999), assim como Sánchez et. al. (2004), exploraram as particularidades e os desdobramentos da expansão desse modelo, como o aumento nos investimentos em áreas urbanas específicas, frequentemente traduzidos, segundo Bienenstein, Sánchez e Vainer (2005), na implantação de Grandes Projetos de Desenvolvimento Urbano (GPDUs). São recorrentes no país os GPDUs em áreas portuárias, em virtude do processo de enfraquecimento da atividade desse setor, localizada em pontos centrais, e da emergência de espaços subutilizados, aos quais são atribuídas vantagens locacionais, como valores paisagísticos e a proximidade de áreas de urbanização consolidada e de ampla oferta de infraestrutura (MONIÉ; VASCONCELOS, 2012).

O primeiro GPDU implantado no Brasil com esse caráter foi o complexo turístico e cultural Estação das Docas, inaugurado em 2000, em Belém (ESTAÇÃO DAS DOCAS, 2020a). Na mesma cidade, vinte anos depois, foi finalizada a primeira etapa da iniciativa Belém Porto Futuro (NUNES, 2020a), que, somando-se a outras intervenções no período, aponta a tendência de concentração de investimentos na orla portuária da cidade. Uma vez que ambos os GPDUs se situam em porções territoriais que historicamente apresentam transformações socioeconômicas semelhantes e configuram um tipo de intervenção na cidade que é representativo das mudanças nas diretrizes do planejamento urbano no país, este artigo tem como 
objetivo central verificar, por meio da análise de ambas as iniciativas, se as características e o processo de implantação de cada uma delas representam mudanças significativas nas diretrizes de planejamento dos GPDUs em Belém, considerando a influência do modelo estratégico de planejamento nas cidades brasileiras.

Os principais temas abordados neste artigo são o desenvolvimento econômico desigual, estudado por autores como Chesnais (1995) e Arrighi (2007), e o conceito de rede global de cidades, proposto por Sassen (2002). Para o desenvolvimento da pesquisa, seguiu-se com a análise das características do planejamento estratégico e de suas particularidades em território nacional com os trabalhos de Arantes (2002), Vainer (1996; 2002; 2007) e Sánchez (1999) e Sánchez et al. (2004). Assim, uma vez verificada a relevância dos GPDUs, aprofundou-se o estudo dessas intervenções por meio de autores como Del Rio (1991), Lungo (2005) e Somekh e Gaspar (2012), em que se identificam as principais dinâmicas associadas a tais iniciativas. Esse é o referencial teórico que sustenta o texto ora apresentado.

Como o planejamento estratégico e os GPDUs foram caracterizados como parte de uma trajetória de transformação no planejamento urbano nacional, foram pesquisados outros conceitos associados às cidades brasileiras, com destaque para a urbanização neoliberal, baseada no conceito de actually existing neoliberalism, que engloba as interações específicas associadas aos diferentes contextos territoriais entre paisagens herdadas e projetos de reestruturação neoliberal voltados ao mercado (BRENNER; PECK; THEODORE, 2005; 2017), e nos estudos de Harvey (1996), cujos desdobramentos em territórios de economia periférica têm o aporte da perspectiva de Cobos (2009; 2013) e de Fix (2007). Estudos a respeito da relação entre as transformações no planejamento urbano e as alterações na configuração do espaço urbano brasileiro também fundamentam a presente pesquisa, a exemplo dos de Vainer (2007) e Rolnik e Klink (2011).

Dados o referencial teórico mencionado e o destaque de Belém em vista dos principais conceitos apontados, o trabalho busca informações do município por meio de dados secundários e de uma pesquisa qualitativa. Foram utilizados os estudos referentes às intervenções na orla portuária da cidade de forma geral, assim como aqueles voltados aos GPDUs, em foco neste trabalho. Adicionalmente, foram considerados relatórios, notícias e informações de órgãos públicos disponíveis sobre a capital paraense.

Perante a pesquisa descrita e o reconhecimento de características e de dinâmicas recorrentes, foram elencados cinco tópicos representativos do planejamento e da gestão dos GPDUs em Belém, referentes às questões de i) aprofundamento da segregação socioespacial; ii) afastamento das intervenções das demandas locais; iii) desarticulação do planejamento urbano como condicionante das iniciativas; 
iv) diminuição da participação do capital privado no financiamento dos empreendimentos e v) ênfase no culturalismo de mercado (ARANTES, 2002).

A primeira seção do trabalho detalha o referencial teórico mencionado, de forma a contextualizar o modelo de planejamento urbano vigente, suas dinâmicas e seus desdobramentos nas cidades brasileiras. Na sequência, é apresentada uma contextualização histórica e socioeconômica de Belém, levando em conta os recortes pertinentes aos GPDUs em análise, e descritos os dois projetos em questão: Estação das Docas e Belém Porto Futuro, inaugurados em 2000 e 2020, respectivamente. Ao final, ambos os GPDUs são analisados com base nos cinco tópicos elencados, de maneira a mapear as divergências e as continuidades entre ambas as requalificações urbanas, como são compreendidos esses Grandes Projetos (MAGALHÃES, 2013), no que se refere às diretrizes do planejamento estratégico.

\section{Alteridade emergente: o planejamento estratégico no Brasil}

A construção do planejamento urbano, sob uma perspectiva histórica, é composta de momentos de transformação emblemáticos, que resultaram em diferentes configurações urbanas, as quais compreendem marcas de diferentes tempos. A partir da década de 1990, a trajetória de ascensão em nível mundial do planejamento estratégico caracterizou um desses momentos, motivada por mudanças econômicas de cunho neoliberal que englobavam condutas como o incentivo às privatizações e a diminuição da atuação do Estado na economia (ARRIGHI, 2007; HARVEY, 1996).

Esse novo modelo de planejamento urbano apresenta características de empresariamento (HARVEY, 1996) da cidade, cujas práticas se voltam para a atração de investimentos privados por meio de instrumentos como o marketing urbano, que, segundo Vainer (2002), consiste em um conjunto de princípios voltados a valorizar e divulgar investimentos e empreendimentos urbanos pontuais. Os objetivos que se pretendem alcançar com o uso desses instrumentos são a mercantilização da imagem; a exploração do sentimento de crise, para a unificação dos cidadãos em torno de consensos; e as parcerias público-privadas, como forma de inserir a cidade em circuitos mercadológicos globais, considerando a conformação de uma rede global de cidades proposta por Sassen (2002) (ARANTES, 2002; HARVEY, 1996; SÁNCHEZ et al., 2004; VAINER, 2002). De maneira geral, apreende-se a subordinação da cidade ao mercado, de forma que ela mesma se torna o produto e passa a configurar uma identidade constituída baseada em demandas e referências externas ao seu contexto histórico, econômico e social.

Por caracterizar-se como incidência exógena, importada de países capitalistas centrais (ARRIGHI, 2007; CHESNAIS, 1995), esse modelo de planejamento 
resultou em uma trajetória particular em âmbito nacional, condicionada pelas características pertinentes ao contexto urbano das economias capitalistas periféricas (VAINER, 2002). Considerando-se a conformação do território preexistente e o processo de urbanização neoliberal na América Latina elucidado por Cobos (2009; 2013), verifica-se que as diretrizes do planejamento estratégico não contemplam características comuns aos contextos urbanos de países periféricos, como a desigualdade social, o déficit habitacional e a carência de infraestrutura urbana básica. Segundo Fix (2007), essa lógica global causa impactos na paisagem urbana, marcada pelo aprofundamento dos desequilíbrios territoriais, com o aumento na concentração de infraestrutura e de investimentos na cidade. Nesse sentido, os GPDUs são pontos-chave para compreender o contexto da disseminação do modelo de planejamento estratégico sobre as cidades, uma vez que operam como mecanismos propulsores desse paradigma.

Introduzidas a partir da segunda metade do século XX, essas iniciativas são reconhecidas pela lógica característica de destinação de recursos para áreas específicas da cidade, por intermédio das quais se busca atrair montantes de investimento privado, sob a promessa de ofertas de empregos, de serviços e da geração de desenvolvimento econômico. Assim, pode-se afirmar que o planejamento e a gestão urbana, voltados a essas iniciativas, enfocam fundamentalmente o recorte espacial destinado aos projetos a serem implantados, o que resulta, também, na concentração de investimentos públicos em melhorias de infraestrutura, recorrentemente associados ao entorno desses projetos (LUNGO, 2005).

Segundo Ezquiaga (apud LUNGO, 2005), os empreendimentos urbanos brasileiros de grande porte objetivam a criação de novas centralidades e a requalificação urbana de áreas históricas, introduzindo critérios de rentabilidade econômica, decorrentes da incorporação do setor privado à gestão dos projetos. Tais critérios favorecem a lógica do mercado sobre os interesses comuns, ocasionando o que Vainer, Oliveira e Lima Júnior (2012) chamam de rupturas na cidade, as quais ocorrem nos âmbitos institucional, urbanístico, legal e político e resultam em uma forma de planejamento urbano caracterizada, principalmente, pela flexibilidade de seus parâmetros e pela submissão a interesses com frequência externos ao seu contexto (VAINER; OLIVEIRA; LIMA JÚNIOR, 2012).

\section{Cidade entreposto: do ciclo da borracha ao planejamento estratégico}

Belém, a capital do estado do Pará, encontra-se no extremo norte do país, com a parte sul de sua orla voltada ao rio Guamá e a parte leste, à baía de Guajará. Sua população, em 2018, foi estimada em 1.485.732, ao passo que o número de habitantes total da região metropolitana, composta de sete municípios, era de 2.491 .052 (FAPESPA, 2020; FNEM, [2018?]). 
O potencial portuário de Belém e seu crescimento urbano foram impulsionados pelo ciclo da borracha, entre os séculos XIX e XX, e com o início do processo de conformação de um porto oficial, em 1897 (ARRUDA, 2003). A ascensão econômica ocasionou a conformação de Belém como o centro urbano da região amazônica brasileira, o que acarretou investimentos em urbanização e embelezamento da cidade. Nesse contexto, o bairro do Reduto e sua área de entorno foram cenário de um desenvolvimento urbano de destaque, como resultado tanto de investimentos públicos como das demandas por modernização da cidade pela elite local. Além de um aterro na área, motivado pela atividade portuária, foram implementadas iniciativas de expansão urbana, com a implantação de linhas de bonde e de equipamentos urbanos, como hotéis, teatro e cinema (ARRUDA 2003; BARROS; SERRA, 2018).

A consolidação de Belém como polo populacional foi fortemente influenciada pelas atividades econômicas associadas ao ciclo da borracha, que provocaram movimentos de imigração para a região metropolitana do município. Essa dinâmica resultou no aumento da população em situação de desemprego e pobreza e desvelou as condições de segregação de investimentos e os grandes vazios de oferta de infraestrutura (PONTE, 2004).

A configuração urbana desigual é reconhecida até hoje em Belém. O bairro do Reduto, com o terceiro maior rendimento médio mensal do município, encontra-se inserido no distrito que apresenta a maior concentração de áreas verdes da cidade; ali, $87 \%$ dos domicílios têm água encanada e em mais de $99 \%$ a coleta de lixo é feita por serviço público. Em contrapartida, menos de 68\% do total de domicílios em Belém conta com esgotamento sanitário, segundo dados de 2010 (IBGE, 2017), o que a coloca atrás de mais de 1.400 municípios brasileiros em que a abrangência desse serviço é maior. Além disso, o rendimento médio da cidade é de 3,4 salários mínimos e apenas $36 \%$ das vias públicas de Belém são consideradas urbanizadas (BELÉM, 2012; IBGE, 2017).

Nos últimos anos, a implantação das iniciativas Mercado Ver-o-Peso, Complexo Ver-o-Rio, Estação das Docas, o novo terminal hidroviário e a recente iniciativa do Belém Porto Futuro, na orla portuária do entorno do bairro do Reduto, evidencia a perpetuação da tendência de concentração de investimentos e infraestrutura na área descrita. É relevante ainda o fato de que, segundo Arruda (2003), tais intervenções, além da proximidade na localização, apresentam conteúdos programáticos similares, voltados ao lazer e a atividades comerciais e turísticas. O mesmo autor pontua que o desenvolvimento desses projetos não é fruto de mecanismos constantes de participação popular, que poderiam legitimar as semelhanças e instigar o questionamento sobre o modo como essas intervenções se relacionam com o planejamento urbano adotado para a cidade de Belém (ARRUDA, 2003; COSTA, 2013). 


\section{Planejamento estratégico recém-chegado: Estação das Docas}

A primeira intervenção a ser implantada foi o complexo turístico cultural Estação das Docas, que se encontra na área do porto de Belém, localizada ao sul da cidade, no bairro Campina, próximo ao centro histórico. A requalificação, pioneira dentre os GPDUS em território nacional, foi inaugurada em 2000 e abrange 3,2 ha de área e $500 \mathrm{~m}$ de orla, incluindo a reforma de antigos armazéns portuários (ESTAÇÃO DAS DOCAS, 2020a; PONTE, 2004). Com recursos advindos de uma parceria público-privada (PPP), o complexo é administrado desde sua abertura por uma entidade pública não estatal, de direito privado, denominada Organização Social Pará 2000 (OS Pará 2000) (ESTAÇÃO DAS DOCAS, 2020a).

O contrato original de gestão, de responsabilidade da Pará 2000, assinala como objetivos para o projeto a "elevação do nível cultural da população”, assim como o "desenvolvimento de uma programação voltada aos segmentos de cultura, de lazer, de turismo e de serviços" e o "desenvolvimento de programação voltada à prestação de serviços essenciais à população de baixa renda e integração com entidades afins buscando permanente cooperação técnica para o alcance de objetivos” (CHAVES, 2019, p. 5). Para além, são listadas como finalidades do empreendimento “desenvolver atividades e serviços de formação, fomento, produção e difusão cultural, capacitação e profissionalização para a indústria de bens culturais, de lazer e turismo" (PARÁ 2000, p. 1, apud CHAVES, 2019, p. 4).

Ademais, as temáticas fixadas no contrato citado foram reafirmadas durante o processo de criação e implantação do complexo Estação das Docas por meio de instrumentos de marketing usados para sua divulgação, em que o desenvolvimento econômico e a geração de renda por meio do incentivo ao turismo e à cultura foram as principais justificativas para a necessidade da estrutura (ESTAÇÃO DAS DOCAS, 2020b).

Esses argumentos são corroborados pela configuração do espaço, que, atualmente, abriga equipamentos de uso cultural, como um anfiteatro, um teatro, um espaço para a realização de feiras, chamado de boulevard, e uma sala multiuso destinada a reuniões corporativas. Também se encontram no local estruturas voltadas ao turismo, como empórios, bares e cafés, um restaurante de comida japonesa e dois quiosques de sobremesas italianas, além de um terminal para a realização de passeios turísticos na baía de Guajará (ESTAÇÃO DAS DOCAS, 2020b; VALEVERDE, 2018).

Contudo, dentre os objetivos propostos, não se verificam aqueles que atenderiam a necessidades da população de baixa renda, como a prestação de serviços essenciais e de serviços de capacitação. Amaral (2005) aponta que não se observou uma participação popular ativa para a configuração do projeto, visto que não houve meios de deliberação popular para a sua definição, apenas medidas consultivas. 
Além dos empecilhos à representação dos interesses populares, o mesmo autor indica a força da atuação dos grupos empresariais no incentivo à implantação do projeto, de forma que os usos propostos para a área são relativos aos interesses de quem tem como principal público consumidor os turistas, ou organizadores e participantes de eventos corporativos de negócios.

Nesse sentido, em face do seu caráter precursor, no processo de implantação do complexo Estação das Docas houve a adesão de instrumentos característicos do planejamento estratégico, como o emprego do marketing urbano, a contribuição do capital privado e o programa de estabelecimentos voltados sobretudo a atividades de setor terciário, com destaque para a exploração do turismo. Adicionalmente, a atribuição da gestão do espaço a uma organização social denota a aproximação da iniciativa privada na administração de GPDUs.

\section{Rupturas contínuas: Belém Porto Futuro}

O projeto de requalificação urbana Belém Porto Futuro está localizado no bairro do Reduto, aproximadamente a $700 \mathrm{~m}$ ao norte do Estação das Docas e ao sul do Complexo Ver-o-Rio. Fruto de uma iniciativa do Ministério da Integração Nacional (MIN), a implantação dessa intervenção foi prevista para ocorrer em três etapas, e a primeira, inaugurada em 2020, consiste na construção de um parque urbano e na remodelação de duas praças já existentes (DIÁRIO ONLINE, 2018; BRASIL, 2020).

Segundo a pesquisa realizada, as etapas ainda não concluídas do Belém Porto Futuro são aquelas relativas à requalificação do Porto Miramar e dos armazéns portuários da área com previsão de estabelecimentos de uso cultural e de serviços (DIÁRIO ONLINE, 2018). É relevante mencionar que não foram encontradas informações detalhadas do projeto junto aos órgãos institucionais consultados, a saber Secretaria de Urbanismo do Pará; Secretaria de Comunicação do Pará; Secretaria de Turismo do Pará; Secretaria de Urbanismo de Belém e Fundação Cultural de Belém.

A instalação do parque urbano em uma área retroportuária foi garantida por meio de uma cessão não onerosa acordada entre o MIN e a Companhia Docas do Pará (CDP), uma empresa de economia mista que é responsável pela administração dos portos do estado do Pará (CDP, 2018). Quanto aos investimentos, para a elaboração do estudo preliminar do projeto, foram alocados $\mathrm{R} \$ 3$ milhões de recursos federais, com um montante total de investimentos públicos da ordem de R \$34,5 milhões na primeira etapa de implantação da intervenção (BRASIL, 2020).

De acordo com o MIN, a concepção programática do Belém Porto Futuro foi realizada em parceria com a população. Foram previstos três encontros, compostos de i) oficina participativa, em junho de 2016; ii) audiência pública em agosto do 
mesmo ano; e iii) outra audiência pública em janeiro de 2017, das quais apenas a audiência de agosto de 2016 foi publicada por meio de chamada pública no Diário Oficial (BRASIL, 2016). Nesse aspecto, é relevante registrar o fato de que houve denúncia do Ministério Público acerca das possibilidades de participação popular no processo de desenvolvimento do projeto, questionando as audiências públicas mencionadas, assim como da inexistência de informações que possibilitassem o acompanhamento das discussões sobre a definição do empreendimento por parte da população (MPF, 2017).

Os veículos de imprensa e os atores do poder público vinculados à implantação do Belém Porto Futuro referem-se à iniciativa de forma semelhante, citando sua construção como o atendimento a uma demanda existente. O lançamento do projeto no website do atual Ministério da Infraestrutura cita: “[...] no ano em que Belém completa 400 anos, a Secretaria de Portos do Ministério dos Transportes, Portos e Aviação Civil devolve à população aquilo que ela mais precisa: espaço” (BRASIL, 2016). Além disso, segundo Iran Lima , deputado estadual do Pará, “essa parte de Belém está totalmente esquecida pela Prefeitura e pelo Governo do Estado. E o projeto do MIN vem suprir essa lacuna” (DIÁRIO ONLINE, 2018).

As menções mais recorrentes encontradas nos principais websites que noticiam a iniciativa, enunciadas também pelos atores envolvidos em sua implantação, foram a busca por impulsionar o desenvolvimento econômico regional; o alinhamento de Belém com as maiores e mais modernas cidades portuárias do mundo; a área portuária como polo de desenvolvimento; a transformação de uma área degradada em um espaço moderno; a atração de investimentos; a geração de emprego e renda; e o estímulo ao turismo (AGÊNCIA BELÉM, CA. 2017; DIÁRIO ONLINE, 2018). Nesse sentido, os eixos de argumentação centrais para a requalificação portuária são o do retorno do espaço para a população e do aumento do desenvolvimento econômico da área. Cabe destacar que, com a justificativa de garantir a segurança do espaço, o Parque Belém Porto Futuro conta com sistema de monitoramento e posto policial, além de ser integralmente cercado, com o acesso às áreas de lazer requalificadas pelo investimento restrito a um período limitado do dia, entre $6 \mathrm{~h}$ e 22h (NUNES, 2020b; GRUPO ORZIL, 2018).

Instrumentos de marketing urbano também foram utilizados para a divulgação do projeto, de forma similar à do empreendimento Estação das Docas, com a apresentação de comparações da iniciativa Belém Porto Futuro com requalificações de áreas portuárias de cidades como Buenos Aires, Barcelona e Rio de Janeiro, a fim de reforçar a ênfase no turismo como principal atividade econômica. Segundo Costa (2013), a exploração dessa imagem ocorre a despeito de conjunturas particulares à cidade, como os altos valores das passagens aéreas, a condição 
socioeconômica geral da população no entorno regional e a distância dos centros de maior poder aquisitivo do país, que se apresentam como obstáculos ante os resultados almejados para o turismo em Belém.

Ademais, o espaço para a realização do projeto foi cedido mediante justificativas específicas, como o atendimento a uma demanda popular existente. No caso do Belém Porto Futuro, além dos meios questionáveis de representação dos interesses da população, a configuração da intervenção inaugurada apresenta barreiras ao pleno uso da área, que podem comprometer tanto sua integração ao entorno como o pleno uso pela população belenense. Essas condições alertam para ações já praticadas no complexo Estação das Docas, como a exploração do turismo e do marketing cada vez mais voltado à integração de Belém ao circuito competitivo de cidades, de modo a articular interesses específicos associados aos GPDUs, ocasionando dinâmicas particulares em decorrência de sua implantação.

\section{A lente sobre o local: marcos temporais em uma trajetória de planejamento}

Tendo em vista as transformações provocadas pela ascensão do planejamento estratégico na escala mundial e por sua importação para o Brasil, assim como o contexto histórico e urbano da cidade de Belém e as características das experiências de GPDUs pesquisadas, foi possível avaliar, como testemunhas das transformações no planejamento de GPDUs na capital paraense, as intervenções Estação das Docas e Belém Porto Futuro. Para a caracterização desse processo, foram definidos cinco pontos principais de análise, cujas delimitações se ancoram nas verificações apresentadas nas quatro primeiras seções do trabalho, considerando a geração tanto de reproduções como de rompimentos com o modelo e as práticas de planejamento estratégico.

\subsection{O simulacro de um centro histórico elitizado}

Dentre as peculiaridades do contexto brasileiro, decorrentes da disseminação do planejamento estratégico e dos GPDUs, despontam desequilíbrios socioespaciais. Nesse sentido, sobressaem os quadros de segregação socioterritorial, conceito que designa a concentração de diferentes classes sociais em certas áreas da cidade em virtude da valorização da terra urbana resultante da concentração de investimentos, motivada, por sua vez, pela urbanização neoliberal (COBOS, 2013; FIX, 2007). Essa segregação é observada pelo afastamento de camadas populares de centros urbanos, submetidos a um urbanismo renovador, processo no qual estão inseridas as requalificações urbanas e portuárias.

De acordo com Mantecón (2009 apud FREITAS, 2010), a configuração estética de um projeto é fator condicionante para o tipo de usuário frequentador do espaço, 
em que barreiras simbólicas são representadas pela "magnificência das construções em que se mostram as ofertas culturais, sua vinculação com a alta cultura e os setores mais ricos” (MANTECÓN, 2009, p. 9, apud FREITAS, 2010, p. 122). Nesse sentido, com base em pesquisa mencionada por Freitas (2010), realizada pela empresa Bureau de Marketing e Pesquisa (BMP), em 2008, com transeuntes e moradores dos bairros de influência direta e indireta do equipamento, verificou-se que os termos mais utilizados para definir o complexo Estação das Docas foram "lindo”, "exuberante" e "luxuoso".

As pesquisas realizadas por Barbalho e Freitas (2011) e Pereira e Matos (2015) revelaram que os usos cotidianos denotam um caráter de apropriação incipiente do espaço. Cabe salientar que parte do público consultado no local para a realização do presente estudo não usufruía da área de alimentação, por conta dos altos valores cobrados pelos serviços, e/ou não sabia citar que tipo de atividades culturais eram promovidas no espaço. Outro resultado relevante diz respeito à opinião de quase metade dos entrevistados, no estudo de 2011: para eles, o complexo seria destinado "somente para ricos" (BARBALHO; FREITAS, 2011; PEREIRA; MATOS, 2015).

No caso do empreendimento Belém Porto Futuro, recém-inaugurado, aspectos de configuração e uso do espaço, como restrição de acesso por horário definido, cercamento das áreas de lazer, a exemplo da praça General Magalhães, e medidas de segurança, como a instalação de sistemas de monitoramento, apontam para uma tendência de gestão de caráter privado do espaço público, que acaba comprometendo a plena acessibilidade da população.

Nesse mesmo sentido, quanto à divulgação do empreendimento nos meios de comunicação, foram encontradas citações referentes aos usos como: "espaço de exposições para artesanato e shows, quiosques com opções de comidas e bebidas típicas, áreas para lazer infantil e centro de convenções” (NUNES, 2020b), assim como menções à estética, com a exploração de características de embelezamento, modernidade e inovação (NUNES, 2020a). Diante da percepção da população sobre o projeto Estação das Docas, cujo programa arquitetônico é semelhante, observa-se que a iniciativa mais recente tende a contribuir para a construção de uma imagem de alto valor econômico agregado ao espaço, o que implicaria a continuidade do afastamento de determinadas parcelas da população.

\subsection{A indiferença pelas demandas locais}

Como já exposto, os GPDUs se constituem como importantes instrumentos de busca pela inserção na rede global de cidades. Em função das diferenças entre as economias centrais e periféricas do sistema capitalista no que se refere ao espaço urbano, a padronização dos projetos e a inexistência de estratégias para 
contemplar as particularidades locais acendem um alerta sobre a correspondência dos GPDUs com as demandas dos territórios em que estão inseridos.

O processo de urbanização brasileiro tem características próprias e é historicamente marcado por ocupações informais, motivadas por déficit habitacional, deficiência na infraestrutura urbana ofertada pelo Estado, zoneamento urbano unifuncional de forte influência modernista e espraiamento da ocupação resultante da busca pelo menor valor das terras (COBOS, 2009; 2013). Em associação com essas condições, Fix (2007) alerta que a diretriz estabelecida pelos mercados globais como condicionante da urbanização neoliberal "justifica metrópoles precárias, sem infraestrutura básica disponível para boa parte da população, e que recursos públicos sejam direcionados para a constituição das chamadas novas centralidades ou eixos de negócios” (FIX, 2007, p. 165).

A cidade de Belém não difere dessa lógica, visto que seu desenvolvimento urbano historicamente desigual resulta em baixos índices de urbanização. Ainda, segundo dados de 2019 (IBGE, 2020), 55,5\% dos habitantes residem em aglomerados subnormais, evidenciando o crescimento urbano à margem do planejamento, e a cidade ocupa a $80^{a}$ colocação em densidade demográfica entre os municípios brasileiros, seguindo a tendência de espraiamento das grandes metrópoles do país (IBGE, 2020; ROLNIK; KLINK, 2011).

No caso do projeto Estação das Docas, seu surgimento e sua consolidação se efetivaram para atender a solicitações advindas de participação popular deliberativa, o que se reflete na análise das demandas do entorno e dos investimentos efetuados pelo complexo. Um exemplo representativo dessas demandas diz respeito à atividade de transporte hidroviário no mercado Ver-o-Peso, que liga Belém ao município de Barcarena e é utilizado diariamente por cerca de 5 mil trabalhadores que realizam o movimento pendular entre as duas cidades. No ano de 2019, o Ministério Público apontou a condição precária do local, sem banheiros ou áreas próprias para a espera, recomendando a retirada dessa atividade do espaço (MPPA, 2019).

Apesar de essa situação se apresentar como uma urgência local, foi implantado junto ao Estação das Docas um terminal hidroviário a ser usado especificamente para passeios turísticos, com ociosidade recorrente (ESTAÇÃO DAS DOCAS, 2020b). A despeito da proximidade entre ambas as estruturas, é possível depreender que os investimentos nessa atividade não objetivaram suprir a demanda existente dos trabalhadores, e sim contemplar o mercado turístico, com usuários ocasionais. Desse modo, expôs-se a omissão antes as questões urbanas da área.

No caso do Belém Porto Futuro, investimentos públicos massivos evidenciam o debate acerca da pertinência da sua aplicação diante das necessidades urbanas prementes na cidade, como infraestrutura urbana básica, notadamente insuficiente em certos pontos da cidade. No bairro Cabanagem, um dos 
aglomerados subnormais da capital, em 2018, o então ministro responsável pela pasta da Integração Nacional autorizou a alocação de 20 milhões de reais em recursos para investimentos em drenagem e pavimentação em uma visita de declaração do início das obras (BRASIL, 2018). Esse recurso é aproximadamente $36 \%$ menor do que aqueles alocados na requalificação portuária em um bairro cuja população é mais de quatro vezes a do bairro do Reduto.

Assim, observa-se que a desvinculação das demandas urbanas existentes, verificada no complexo Estação das Docas, se perpetua, vinte anos depois, no projeto Belém Porto futuro. A concentração de investimentos na orla não é resultado do atendimento de solicitações populares, as quais tiveram pouco espaço de representação em ambos os projetos. Esse panorama indica, portanto, que as intervenções de requalificação em Belém correspondem à vertente de GPDUs que, segundo Morandi e Pucci (1998 apud SOMEKH; GASPAR, 2012, p. 136), pretendem atender às necessidades do mercado, e não às da população.

\subsection{As estratégias de desarticulação do planejamento}

O modelo estratégico de planejamento da cidade baseia-se, entre outros princípios, na descentralização dos processos de tomada de decisão, os quais favorecem os aspectos mercadológicos dos investimentos. De acordo com Sánchez (1999), os novos agentes econômicos envolvidos, como empresários e investidores do ramo imobiliário, têm avançado com o propósito de exercer pressão sobre os instrumentos tradicionais de planejamento, como documentos técnicos e planos diretores. Assim, preza-se pela atração de investimentos segundo estratégias de acumulação de capital sobre áreas isoladas na cidade, que pouco se articulam com o contexto em que se inserem e com as políticas de planejamento e gestão vigentes.

Seguindo essa concepção, Castro e Figueiredo (2013) questionam aspectos de gestão do complexo Estação das Docas durante a primeira década dos anos 2000 e apontam que, ainda que uma de suas principais atividades econômicas seja o turismo, a entidade então responsável pela coordenação desse setor no estado, a Companhia Paraense de Turismo (Paratur), não esteve presente nos espaços de decisão promovidos pela OS Pará 2000. No período, foi estabelecido um conselho administrativo com representantes da iniciativa privada, entidades civis e outros órgãos públicos, como a Secretaria de Cultura do Estado (Secult). Da mesma forma, vale ressaltar que a Pará 2000 não participou dos debates do Fórum Estadual de Turismo (Fomentur), em que foram discutidas políticas para o desenvolvimento do turismo no estado (CASTRO; FIGUEIREDO, 2013).

Dentre as semelhanças observadas entre os dois GPDUs analisados, destaca-se, além da localização, a opção por centros culturais, quiosques de alimentação e 
teatros em seus espaços (CDP, 2017). Detecta-se assim uma incoerência em relação às diretrizes e objetivos estabelecidos no Plano Diretor do Município (PDM), em que se apresenta a descentralização das atividades culturais e das atividades terciárias nos objetivos das seções de "Política de Patrimônio Cultural" e "Ordenamento Territorial”, respectivamente (BELÉM, 2008, p. 15 e 41). Outro aspecto que não corresponde ao previsto no PDM diz respeito às áreas verdes (praças) presentes no projeto concebido, que não se inserem em nenhum programa municipal ou ação global da cidade relativo à recuperação de áreas degradadas, como consta nas diretrizes da seção "Sistema Municipal de Áreas Verdes e de Lazer” do documento (BELÉM, 2008, p. 34).

Constata-se, portanto, que houve continuidade nas dissonâncias de coordenação entre a esfera pública e os GPDUs, no tocante a ambos os empreendimentos. Enquanto a gestão do Estação das Docas ocorre a despeito dos princípios norteadores de fomento ao turismo discutidos pelo órgão estadual responsável, o Belém Porto Futuro se desvincula das diretrizes e objetivos previstos pelo principal instrumento de planejamento urbano vigente. Reforça-se, ademais, o caráter análogo entre os programas definidos para os projetos, que, além de saturar o espaço urbano com serviços e atividades já existentes, concentram investimentos que poderiam ser empregados em outras áreas da cidade, em concordância com o preconizado pelos documentos de planejamento urbano vigentes.

\subsection{A ausência do capital privado no financiamento das requalificações}

$\mathrm{Na}$ implantação de projetos urbanos no contexto do planejamento estratégico, buscam-se práticas de legitimação dos interesses do mercado, dentre as quais desponta o enfraquecimento da separação entre o setor público e o privado. Contudo, apesar de o financiamento de intervenções urbanas por intermédio de PPPs ser uma estratégia característica desse modelo de planejamento, há questionamentos quanto à efetivação da participação financeira do ente privado na implantação dos GPDUs em Belém.

A obra do complexo Estação das Docas foi orçada em R \$ 6,2 milhões, valor indicado no contrato inicial. Entretanto, o GPDU em questão foi inaugurado a um custo final de $\mathrm{R} \$ 24$ milhões, dos quais $\mathrm{R} \$ 19$ milhões foram financiados pelo Estado e R\$ 5 milhões investidos pela iniciativa privada. Embora um dos aspectos da publicidade do empreendimento tenha sido sua efetivação mediante financiamento privado, este representou apenas $21 \%$ do total da verba empregada na sua implantação (FREITAS, 2010). Ainda, uma vez realizado o alto investimento público inicial, o local foi cedido ao setor privado para exploração das áreas, sem vinculação de reposição de valores investidos aos cofres públicos ou previsão de qualquer outra contrapartida (BIENENSTEIN; SÁNCHEZ; VAINER, 2005). 
A OS Pará 2000 apresentou como meta tornar a intervenção Estação das Docas autossustentável em um prazo de um ano após sua inauguração. Contudo, passados quatro anos, o complexo gerou prejuízos financeiros. Assim, visando à continuidade do seu funcionamento, o Governo Estadual do Pará passou a subsidiar os custos operacionais do espaço com aproximadamente $\mathrm{R} \$ 70.000,00$ por mês, majoritariamente destinados à climatização dos estabelecimentos comerciais presentes no empreendimento, consolidando a relevância do poder público para a manutenção da estrutura (MENDONÇA, 2014).

Quanto ao projeto Belém Porto Futuro, ainda que nos meios midiáticos o Ministério da Infraestrutura tenha promovido a iniciativa privada como a responsável pela maior parte dos investimentos (BRASIL, 2017), poucas informações foram divulgadas acerca da origem dos recursos. De todo modo, pesquisas efetuadas sobre os dados disponibilizados pelo governo federal permitiram verificar que o projeto de requalificação da área retroportuária de Belém contou com um investimento de R \$ 34,5 milhões provindos da Secretaria Nacional de Desenvolvimento Regional, referentes à primeira etapa do empreendimento (BRASIL, 2020).

Contrariando as estratégias divulgadas para ambos os projetos, constata-se a existência de desequilíbrio na proporção entre os investimentos privados e públicos nos GPDUs em foco. Esse contexto ocasiona assimetria nos benefícios e contrapartidas das PPPs analisadas, possibilitando a exploração das vantagens econômicas das intervenções por parte do ente privado com a oneração do Estado, que tem comprometida sua atuação como regulador da distribuição de investimentos na cidade, fomentando os desequilíbrios territoriais historicamente verificados.

\subsection{A ênfase no culturalismo de mercado}

O planejamento estratégico tem como diretrizes a construção e a consolidação popular de uma referência de patriotismo associada a um sentimento conjunto de crise, que visa à legitimação e à concretização de intervenções - como os GPDUs - como soluções ideais (ARANTES, 2002; VAINER, 2002). Nesse sentido, a função dos agentes que integram as iniciativas norteadas por essas diretrizes envolve a disseminação de motivações específicas entre os cidadãos, apoiadas na criação de um ideal comum, por meio do uso de mecanismos de controle social para a garantia de seus interesses (ARANTES, 2002; SÁNCHEZ, 1999).

De acordo com Arantes (2002), a cultura tornou-se peça central no processo de configuração urbana de cidades-empresa, nas quais cada vez mais o capital assume o protagonismo. Essa estratégia visa tanto ao fortalecimento da sensação de patriotismo ou pertencimento coletiva como ao estabelecimento de uma identidade para o marketing urbano, baseada em pilares culturais locais, comercializáveis 
aos visitantes. Nesse contexto, o planejamento da cidade é convertido em empresariamento urbano sob o manto cultural, o que, em Belém, se constata pelo destaque a determinados costumes que se sobrepõem às mazelas sociais vivenciadas no espaço, em prol de maior rentabilidade das intervenções urbanas (ARANTES, 2002).

Assim, o culturalismo de mercado na capital belenense ganha uma feição específica: a comercialização da tradição amazônica, que se manifesta tanto nos usos encontrados nos GPDUs como na mídia e nas declarações atribuídas às intervenções (BARBALHO; FREITAS, 2011). Eis a primeira mensagem exibida ao acessar o website da intervenção Estação das Docas: "Estação das Docas é um dos espaços que mais refletem a região amazônica” (ESTAÇÃO DAS DOCAS, 2020b). Esse ponto pode ser observado também nos nomes dos estabelecimentos do complexo, que fazem referência à região amazônica e à cultura indígena, como Amazon Beer, Bombom do Pará, As Mulatas e o Boulevard Marajoara. Da mesma forma, é comum a realização de apresentações alusivas ao folclore regional e ao carimbó, ritmo musical amazônico. Todavia, segundo Pontes (2002 apud BIENENSTEIN; SÁNCHEZ; VAINER, 2005, p. 11),

[...] vale destacar que tal iniciativa, embora se aproveite de alguns aspectos da cultura local - especialmente a culinária -, está fortemente baseada em concepções, procedimentos e práticas exógenas, calcadas em modelos trazidos de outras cidades inseridas mais decisivamente no circuito das metrópoles do mundo capitalista [...].

As tentativas de criação de uma imagem acabam por privilegiar manifestações culturais passíveis de serem exploradas como mercadoria (BARBALHO; FREITAS, 2011; PARÁ, 2012). O Estação das Docas representa uma referência estratégica para o marketing urbano de Belém por demarcar a identidade paraense na tentativa de delinear a imagem de coesão social, política e cultural, capaz de atrair um público consumidor externo, de caráter central na atividade turística para a qual se destinam as intervenções (BARBALHO; FREITAS, 2011).

O projeto Belém Porto Futuro, por sua vez, apesar de também veicular em suas estratégias de marketing fatores alusivos ao processo histórico de ocupação da região, como a integração da cidade com o porto e com os corpos d’água, ainda não apresentou, na primeira etapa de execução do projeto, um processo claro de comercialização da identidade cultural. Ressalta-se que as próximas etapas previstas incluem a requalificação dos armazéns portuários da área, a exemplo das ações realizadas no complexo Estação das Docas, reproduzindo uma prática já efetivada que propicia maior espaço de exploração de estratégias dessa natureza. 


\section{Considerações finais}

Por meio da análise das iniciativas Estação das Docas e Belém Porto Futuro e da associação de suas características às diretrizes de planejamento estratégico, pôde-se verificar a manutenção de alguns dos pilares principais desse modelo. De forma geral, encontram-se nos GPDUs da capital paraense referências a estratégias internacionais, como o agravamento da concentração de investimentos, a garantia dos interesses mercadológicos, a oneração do Estado, o enfraquecimento da construção coletiva do planejamento e o aprofundamento da segregação socioterritorial. Cabe, portanto, destacar algumas relações pertinentes a ambas as iniciativas, que corroboram a tônica da descentralização dos processos de tomada de decisão e da desarticulação do planejamento urbano, perpetuando dissociações da realidade local.

No que diz respeito ao aspecto territorial, salienta-se o agravamento da acumulação de capital sobre espaços valorizados de Belém, pela implantação de empreendimentos como os GPDUs, segundo os princípios do planejamento estratégico. Essa particularidade, preservada pelo complexo Estação das Docas, reafirma-se no Belém Porto Futuro não apenas pela proximidade geográfica das estruturas, como também pela semelhança dos usos e estabelecimentos, que se apoiam na reprodução de diretrizes de planejamento internacionais, em detrimento de objetivos e diretrizes de descentralização estabelecidos pelo Plano Diretor Municipal.

Nesse sentido, é possível inferir que o direcionamento do planejamento da cidade, com base na análise dos GPDUs, mostra gradativo afastamento dos investimentos das questões urbanas pungentes, tanto pela redução dos meios de representação como pela indiferença aos instrumentos de planejamento urbano vigentes, que, por lei, abarcam práticas da participação popular. Os poucos espaços de participação em ambas as iniciativas não resultaram no atendimento das demandas verificadas na cidade de Belém e tampouco se ancoraram nos estudos e diagnósticos já realizados, os quais foram, inclusive, fonte de informações para as reflexões do presente trabalho. Essa constatação indica que o planejamento estratégico na capital paraense se consolidou por meio de práticas que correspondem a modelos externos e ao estabelecimento de condições de apropriação dos investimentos públicos pelo mercado, cuja ocorrência, a despeito do contexto municipal local, ratifica rupturas na cidade de Belém, de cunho institucional e legal, mas também econômico e social.

Em relação aos investimentos, um aspecto contraditório pode ser observado em face do desequilíbrio verificado nas PPPs. As iniciativas privadas, apesar da representação de seus interesses em ambos os GPDUs estudados, tiveram participação pouco expressiva no que se refere ao financiamento. Esse panorama é comprovado expressivamente logo na primeira requalificação analisada e na primeira 
etapa da segunda requalificação, não obstante ambas explorem a legitimação das intervenções nas respectivas publicidades, sob pretexto de desoneração do Estado. Em vista disso, reitera-se a consolidação do papel do poder público como facilitador da acumulação de capital no território, com responsabilidade, também, sobre a manutenção de estruturas econômicas e jurídicas que propiciam vantagens para o setor privado, em uma postura característica do planejamento estratégico. Para o contexto de Belém, essa condição tende a agravar cenários de desequilíbrio de investimentos urbanos historicamente estabelecidos, prolongando os contrastes observados na ocupação territorial, a exemplo dos bairros do Reduto e Cabanagem, sem a devida intervenção sobre as carências mais urgentes existentes ou sobre as condições de vida de populações que estão à margem das áreas requalificadas.

Para além disso, o distanciamento das iniciativas do contexto histórico e urbano local é corroborado como produto de decisões políticas e administrativas acumuladas ao longo dos últimos vinte anos. Todas as conclusões apontadas pela análise indicam perpetuação da abdicação dos interesses populares, em favor da busca pelo atendimento às demandas externas impostas pela lógica global de competição entre cidades, que se mostra cada vez mais coercitiva sobre as administrações municipais. Em contrapartida, considerando os redirecionamentos recentes de administração da capital paraense, que assume diretrizes colaborativas e participativas como orientação de governo, estabelece-se como desafio a priorização dos instrumentos de planejamento urbano da cidade, legitimados pela população, com a retomada da atuação do poder público no contexto de investimentos e políticas urbanos, pautados na escala local.

Os próximos passos da gestão da cidade devem ser acompanhados pela sociedade civil belenense, de forma a garantir que esses princípios sejam exercidos, inclusive ao longo da implantação das próximas etapas do Belém Porto Futuro. É desejável, também, a continuidade de estudos nessa temática para a avaliação da influência dos aspectos apontados nas posturas de administração e planejamento urbano locais.

\section{Referências}

AGÊNCIA BELÉM. Porto Futuro deve mudar a face de Belém. [CA. 2017]. Disponível em: http:// agenciabelem.com.br/. Acesso em: 13 nov. 2020.

AMARAL, B. D. M. A guerra das águas: concepções e práticas de planejamento e gestão urbana na orla fluvial de Belém (PA). 2005. 232 p. Dissertação (Pós-graduação em Política de Desenvolvimento Regional) - Universidade Federal do Pará, Belém, 2005.

ARANTES, O. Uma estratégia fatal. A cultura nas novas gestões urbanas. In: ARANTES, O.; VAINER, C. B.; MARICATO, E. A cidade do pensamento único: desmanchando consensos. Petrópolis: Vozes, 2002. 
ARRIGHI, G. Globalização e desenvolvimento desigual. Revista de Estudos e Pesquisas sobre as Américas, v. 1, n. 1, ago.-dez. 2007.

ARRUDA, E. S. Porto de Belém do Pará: origens, concessão e contemporaneidade. 2003. 237 p. Dissertação (Mestrado em Planejamento Urbano e Regional) - Universidade Federal do Rio de Janeiro, Rio de Janeiro, 2003.

BARBALHO, A.; FREITAS, A. P. N. de. Política cultural e consumo na região amazônica: um estudo dos públicos da Estação das Docas em Belém do Pará. Revista Alveu, v. 12, n. 23, p. 130-142, jul.-dez. 2011.

BARROS, M. C; SERRA, H. H. A Belém da Belle Époque e os roteiros geoturísticos como instrumentos de educação patrimonial. Revista Formação, v. 25, n. 44, p. 209-239, jan.-abr. 2018. versão online. Disponível em: https://revista.fct.unesp.br/index.php/formacao/article/view/5163. Acesso em: 20 abr. 2021.

BELÉM. Lei no 8.655, de 30 de julho de 2008. Dispõe sobre o Plano Diretor do Município de Belém, e dá outras providências. Diário Oficial [do] Município de Belém, Belém, PA, n. 11214, 5 set. 2008.

BELÉM. Prefeitura Municipal. Anuário Estatístico do Município de Belém, v. 16, 2011. Belém: Secretaria Municipal de Coordenação Geral do Planejamento e Gestão, 2012. p. 411.

BIENENSTEIN, G.; SÁNCHEZ, F.; VAINER, C. Grandes intervenções nas metrópoles brasileiras: um contraponto entre os projetos Ver-o-Peso e Estação das Docas em Belém do Pará. In: ENCONTRO NACIONAL DA ANPUR, 11, Salvador. Anais do XI Encontro Nacional da Anpur. Salvador: Anpur, maio 2005.

BRASIL. Portaria $\mathrm{n}^{\circ}$ 278, de 28 de julho de 2016. Diário Oficial da União, seção 1, Brasília, DF, $\mathrm{n}^{\mathrm{0}}$ 145, 29 jul. 2016.

BRASIL. Ministério da Infraestrutura. Projeto de Revitalização - Belém Porto Futuro. 13 jan. 2017. Disponível em: http://canaldoservidor.infraestrutura.gov.br/estudos-e-pesquisas/9o-portos-p\%C3\%A1gina-inicial/5495-projeto-de-revitaliza\% $\% \mathrm{C}_{3} \% \mathrm{~A} 7 \% \mathrm{C}_{3} \% \mathrm{~A} 30-$-bel\%C3\%Agm-porto-futuro.html. Acesso em: 13 nov. 2020.

BRASIL. Ministério do Desenvolvimento Regional. Projeto Belém Porto Futuro irá revitalizar área retroportuária da capital paraense. Brasília, DF, 14 nov. 2018. Disponível em: https://bit.ly/3ftVUP2. Acesso em: 13 nov. 2020.

BRASIL. Inaugurada primeira fase do projeto Belém Porto Futuro. 13 ago. 2020. Disponível em: https://www.gov.br/pt-br/noticias/transito-e-transportes/2020/08/inaugurada-primeira-fase-do-projeto-belem-porto-futuro. Acesso em: 12 nov. 2020.

BRENNER, N.; PECK, J.; THEODORE, N. Neoliberalism urbanism: cities and the rule of markets. In: BRIDGE, G.; WATSON, S. (ed.) The New Blackwell Companion to the City, 2005.

BRENNER, N.; PECK, J.; THEODORE, N. Actually existing neoliberalism. The Sage Handbook of Neoliberalism, p. 3-33, jan. 2017.

CASTRO, C. A. T.; FIGUEIREDO, S. Turismo, políticas públicas e espaços públicos urbanos: a Estação das Docas em Belém, Pará. In: AZEVEDO, F. F. et al. Turismo em foco. Belém: Naea, 2013. p. 189-202. 
CDP. Companhia Docas do Pará. Plano de Desenvolvimento e Zoneamento Portuário - Porto Organizado de Belém/PA. Belém: CDP, 2017.

CDP. Companhia Docas do Pará. Contratos de cessão de uso. 2018. Disponível em: https:// www.cdp.com.br/contratos-de-cessao-de-uso. Acesso em: 13 nov. 2020.

CHAVES, D. A. Organizações sociais nos espaços públicos na cidade de Belém: suas relações com o Estado e modelos de avaliação. In: XLIII ENCONTRO DA ASSOCIAÇÃO NACIONAL DE PESQUISA E PÓS-GRADUAÇÃO EM ADMINISTRAÇÃO. 2019, São Paulo. Anais [...]. São Paulo: Anpad, 2019.

CHESNAIS, F. A globalização e o curso do capitalismo de fim de século. Economia e Sociedade, Campinas, n. 5, p. 1-30, dez. 1995.

COBOS, E. P. Los Territórios del neoliberalismo en America Latina: compilación de ensayos. Xochimilco, Ciudad de Mexico: Universidad Autónoma Metropolitana; Miguel Ángel Porrua Editor, 2009. 344p.

COBOS, E P. La ciudad capitalista en el patrón neoliberal de acumulación en América Latina. Cadernos Metrópole, São Paulo, v. 16, n. 31, p. 37-70, jun. 2013.

COSTA, B. J. M. Gestão de orla urbana e turismo sustentável: reflexões e proposições a partir do projeto do Complexo Ver-o-Rio em Belém (PA). 2013. Dissertação (Mestrado) Universidade Federal do Pará, Belém, 2013. 116p.

DEL RIO, V. Desenho urbano e revitalização na área portuária do Rio de Janeiro: a contribuição do estudo da percepção ambiental. 1991. Tese (Doutorado) - Universidade de São Paulo, São Paulo, 1991.

DIÁRIO ONLINE. Helder inicia obras do Belém Porto Futuro. 15 mar. 2018. Disponível em: https://www.diarioonline.com.br/noticias/para/noticia-493797-helder-inicia-obras-do-belem-porto-futuro.html. Acesso em: 13 nov. 2020.

ESTAÇÃO DAS DOCAS. Estação das Docas. [2020a]. Disponível em: http://www.estacaodasdocas.com/. Acesso em: 13 nov. 2020.

ESTAÇÃO DAS DOCAS. Nossos espaços. [2020b]. Disponível em: http://www.estacaodasdocas. com/mix-lojas/. Acesso em: 13 nov. 2020.

FAPESPA. Fundação Amazônica de Amparo a Estudos e Pesquisas. Anuário Estatístico do Pará 2020: população total e estimativas populacionais, Pará e municípios - 2016 a 2020. Pará, 2020. Disponível em: www.fapespa.pa.gov.br/sistemas/anuario2020/tabelas/demografia/tab-1.1-populacao-total-e-estimativas-populacionais-2016-a-2020.htm. Acesso em: 16 abr. 2021.

FIX, M. São Paulo, cidade global: fundamentos financeiros de uma miragem. São Paulo: Boitempo, 2007. 192 p.

FNEM. Fórum Nacional de Entidades Metropolitanas. Região Metropolitana de Belém. Belém: FNEM, [2018?].

FREITAS, N. P. A. Políticas culturais e consumo cultural: um estudo dos públicos da Estação das Docas em Belém/PA. 2010. 147p. Dissertação (Mestrado em Políticas Públicas e Sociedade) - Universidade Estadual do Ceará, Fortaleza, 2010. 
GRUPO ORZIL. Projeto Belém Porto Futuro. 2018. Disponível em: https://www.orzil.org/noticias/projeto-belem-porto-futuro/. Acesso em: 11 nov. 2020.

HARVEY, D. Do gerenciamento ao empresariamento: a transformação da administração urbana no capitalismo tardio. Espaço \& Debates, São Paulo, n. 39, p. 48-64, 1996.

IBGE. Instituto Brasileiro de Geografia e Estatística. Cidades. Panorama. Censo Demográfico 2010. Rio de Janeiro: IBGE, 2017.

IBGE. Instituto Brasileiro de Geografia e Estatística. Quase dois terços das favelas estão a menos de dois quilômetros de hospitais. Censo 2021. IBGE, 19 maio 2020. Disponível em: https://bit.ly/3n2DzdP. Acesso em: 16 abr. 2021.

LUNGO, M. Grande Proyectos Urbanos: Una Visión General. Urbana, Caracas, v. 10, n. 37, p. 15-45, jul. 2005.

MAGALHÃES, I. Planos locais de habitação. In: DENALDI, R. (org.). Planejamento habitacional: notas sobre a precariedade e terra nos planos locais de habitação. São Paulo: Annablume, 2013. p. 13-28.

MENDONÇA, A. S. Grandes Projetos Urbanos e gestão pública: a renovação da área portuária do Recife. 2014. 179 p. Dissertação (Pós-graduação em Desenvolvimento Urbano) Universidade Federal de Pernambuco, Recife, 2014.

MONIÉ, F.; VASCONCELOS, F. N. Evolução das relações entre cidades e portos: entre lógicas homogeneizantes e dinâmicas de diferenciação. Confins: Revista franco-brasileira de geografia, v. 15, n. 15, p. 3, jul. 2012. Disponível em: https://journals.openedition.org/confins/7685. Acesso em: 13 nov. 2020.

MPF. Ministério Público Federal. MPF abre inquérito para investigar regularidade de projeto de revitalização da região portuária de Belém. 16 jun. 2017. Disponível em: https://bit. ly/3cEgN8x. Acesso em: 13 nov. 2020.

MPPA. Ministério Público do Estado do Pará. MPPA quer mudanças em embarque de passageiros no Ver-o-Peso, 10 jul. 2019. Disponível em: https://bit.ly/3mjNZp7. Acesso em: 13 nov. 2020.

NUNES, L. Primeira etapa do Porto Futuro é entregue aos paraenses. Agência Pará, Belém, 13 ago. 2020 [2020a]. Disponível em: https://agenciapara.com.br/noticia/21444/. Acesso em: 13 nov. 2020.

NUNES, L. Estado abre Parque Urbano Belém Porto Futuro e vai instalar mais de 100 árvores, Agência Pará, Belém, 19 ago. 2020 [2020b]. Disponível em: https://agenciapara.com.br/ noticia/21575/. Acesso em: 11 nov. 2020.

PARÁ. Ver-o-Pará: Plano Estratégico de Turismo. Pará: Relatório Executivo, 2012. 92 p.

PEREIRA, P. V. V.; MATOS, L. L. da S. Lazer como mecanismo de apropriação democrática dos espaços públicos: um estudo s obre as práticas de lazer na estação das docas em Belém (Pará, Brasil). Turismo e Sociedade, Curitiba, v. 8, n. 3, p. 511-531, set.-dez. 2015.

PONTE, X. P. J. A orla de Belém: intervenções e apropriação. 2004. 212 p. Dissertação (Mestrado em Planejamento Urbano e Regional) - Universidade Federal do Rio de Janeiro, Rio de Janeiro, 2004. 
ROLNIK, R.; KLINK, J. Crescimento econômico e desenvolvimento urbano: por que nossas cidades continuam tão precárias? Novos estudos CEBRAP, São Paulo, n. 89, p. 89-109, 2011.

SÁNCHEZ, F. Políticas urbanas em renovação: uma leitura crítica dos modelos emergentes. Porto Alegre: ANPUR, 1999.

SÁNCHEZ, F. et al. Produção de sentido e produção do espaço: convergências discursivas nos grandes projetos urbanos. Revista Paranaense de Desenvolvimento, Curitiba, n. 107, p. 39-56, jul.-dez. 2004.

SASSEN, S. Locating cities on global circuits. Environment \& Urbanization, London, v. 1, n. 14, p. 13-30, abr. 2002.

SOMEKH, N.; GASPAR, R. C. Capital excedente e urbanização: o papel dos Grandes Projetos Urbanos. Revista Brasileira de Estudos Urbanos e Regionais, v. 14, n. 2, p. 133-146, nov. 2012.

VAINER, C. B. Os liberais também fazem planejamento urbano? Glosas ao "Plano Estratégico da Cidade do Rio de Janeiro”. Proposta, Rio de Janeiro, ano 24, n. 69, p. 28-34, 1996.

VAINER, C. B. Pátria, empresa e mercadoria: notas sobre a estratégia discursiva do planejamento estratégico urbano. In: ARANTES, O.; VAINER, C. B., MARICATO, E. A cidade do pensamento único: desmanchando consensos. Petrópolis: Vozes, 2002.

VAINER, C. B. Planejamento territorial e projeto nacional: os desafios da fragmentação. Revista Brasileira de Estudos Urbanos e Regionais, São Paulo, v. 9, n. 1, p. 9-23, 2007.

VAINER, C. B.; OLIVEIRA, F. de; LIMA JÚNIOR, P. de N. Notas metodológicas sobre a análise de grandes projetos urbanos. In: OLIVEIRA, F. de et al. Grandes Projetos Metropolitanos: Rio de Janeiro e Belo Horizonte. Rio de Janeiro: Letra Capital, 2012.

VALEVERDE TURISMO. Orla ao entardecer. [2018]. Disponível em: https://www.valeverdeturismo.com.br/produto/10o/5/1968/orla-ao-entardecer. Acesso em: 13 nov. 2020. 


\section{Maria Eduarda Iesbich Arruda}

Arquiteta e urbanista pela Universidade Federal de Santa Catarina (UFSC), com mestrado em Geografia na área de Desenvolvimento Regional e Urbano pela mesma instituição.

Email: mariaeduarda.iesbich@gmail.com

ORCID: 0000-0002-3225-9936

Contribuição de autoria: conceituação; curadoria de dados; análise formal; investigação/pesquisa; metodologia; supervisão/orientação; validação; escrita - primeira redação; escrita - revisão e edição.

\section{Aleph Tonera Lucas}

Graduando em Arquitetura e Urbanismo pela Universidade Federal de Santa Catarina (UFSC).

Email: alephtonera@gmail.com

ORCID: 0000-0001-6704-2764

Contribuição de autoria: conceituação; curadoria de dados; análise formal; investigação/pesquisa; metodologia; validação; escrita - primeira redação; escrita - revisão e edição.

\section{Luísa Siqueira Doebeli}

Graduanda em Arquitetura e Urbanismo pela Universidade Federal de Santa Catarina (UFSC).

Email: Iusiqueiradoebeli@gmail.com

ORCID: 0000-0002-1100-5304

Contribuição de autoria: conceituação; curadoria de dados; análise formal; investigação/pesquisa; metodologia; validação; escrita - primeira redação; escrita - revisão e edição. 
Submissão: 5 de junho de 2020.

Aprovação: $1^{\circ}$ de março de 2021 .

Como citar: ARRUDA, M. E. I; LUCAS, A. T.; DOEBELI, L. S. Integração global e dissociação local: uma análise temporal do planejamento de GPDUs por meio dos projetos Estação das Docas e Belém Porto Futuro. Revista brasileira de estudos urbanos e regionais. v. 23, E202113, 2021. DOI 10.22296/2317-1529.rbeur.202113

Artigo licenciado sob Licença Creative Commons CC BY 4.0.

https://creativecommons.org/licenses/by/4.o/deed.pt_BR 